\title{
菏 University
}

Dimoula, M., Kotronoulas, G., Katsaragakis, S., Christou, M., Sgourou, S. and Patiraki, E. (2019) Undergraduate nursing students' knowledge about palliative care and attitudes towards end-of-life care: a three-cohort, cross-sectional survey. Nurse Education Today, 74, pp. 7-14. (doi:10.1016/j.nedt.2018.11.025)

There may be differences between this version and the published version. You are advised to consult the publisher's version if you wish to cite from it.

\section{http://eprints.gla.ac.uk/176854/}

Deposited on: 18 July 2019

Enlighten - Research publications by members of the University of Glasgow http://eprints.gla.ac.uk 


\title{
UNDERGRADUATE NURSING STUDENTS' KNOWLEDGE ABOUT PALLIATIVE CARE AND ATTITUDES TOWARDS END-OF-LIFE CARE: A THREE-COHORT, CROSS-SECTIONAL SURVEY
}

Dimoula Maria ${ }^{1}$, Kotronoulas Grigorios $^{2}$, Katsaragakis Stylianos ${ }^{3}$, Christou Maria ${ }^{3}$, Sgourou Stavroula ${ }^{3}$, Patiraki Elisabeth ${ }^{3}$

1. National and Kapodistrian University of Athens, Athens, Greece Electronic address :mariadml@yahoo.gr

2. University of Glasgow, Glasgow, United Kingdom

3. National and Kapodistrian University of Athens, Athens, Greece

Words:4660

\begin{abstract}
Background: Ensuring adequate knowledge about palliative care and positive attitudes towards death and dying are crucial educational aspects when preparing undergraduate nursing students to respond effectively to the complexities of care for people affected by a progressive, life-limiting illness. In undergraduate nursing education in Greece, the level of students' attained knowledge and developed attitudes towards palliative and end-of-life care remain unknown.
\end{abstract}

Purpose: To investigate undergraduate nursing students' knowledge about palliative care and attitudes towards death and end-of-life care, and explore demographic and academic factors as potential moderators of student knowledge and attitudes.

Methods: We conducted a descriptive, cross-sectional, questionnaire-based survey. We recruited $2^{\text {nd }}, 3^{\text {rd }}$ and $4^{\text {th }}$ year undergraduate nursing students from the country's two University Faculties. Participants completed a demographic form, the Palliative Care Quiz for Nursing (PCQN), and the Frommelt Attitudes Towards Care of the Dying (FATCOD) questionnaire.

Results: The final sample was 529 students (response rate=87.6\%). Mean total PCQN scores revealed low levels of knowledge. Knowledge about pain/symptom management and psychosocial/spiritual care was insufficient. Mean total FATCOD scores indicated positive, liberal and supportive attitudes towards end-of-life care, with $60 \%$ of respondents keen to care for a dying person and their family. We noted less positive attitudes mainly in relation to student comfort with the care of a dying person and his/her imminent death. Academic parameters (year of study) and student demographic characteristics (older age) were the most significant moderators of both knowledge and attitudes. Greater knowledge about palliative care was a relatively weak, yet significant, predictor of more liberal attitudes towards care of the dying.

Conclusion: Our findings suggest that structured courses in palliative care can be a core part of undergraduate nursing education. Specific attention could be given to such areas patient-health professional communication, misconceptions and biases towards death and dying, and comfort in caring for the dying in order to prepare student nurses to psychologically deal with the sensitive and challenging process of death and dying. 


\section{Background}

The volume of patients with progressive, life-limiting illnesses that require care in the final year(s) (i.e. palliative care) or final week(s) of life (i.e. end-of-life care) is increasing steadily (Etkindet al., 2017). Nurses' competence to actively and holistically assess and address the needs of people receiving palliative and end-oflife care is paramount (Chover-Sierra, Martínez-Sabater and Lapeña-Moñux, 2017). Hence, the requirement for continuing, evidence-based nursing education on the principles and goals of palliative and end-of-life care is pressing(Kwekkeboom, Vahl and Eland, 2006).

Inadequate knowledge can hinder provision of high-quality nursing care(Al Qadire, 2014), potentially leading to nurses feeling poorly prepared and stressed when caring for a person with palliative and end-of-life care needs (Araujo Sadala and Machado da Silva, 2009; Mutto et al., 2010). Such feelings can contribute to the development or exacerbation of negative attitudes towards death and caring for the dying that may further impact on the standard of care(Brajtmanet al., 2007; Wang et al., 2016). Attitudes towards death and care for the dying are psychological behaviors learned as part of a person's social and cultural experiences during his/her lifetime(Mastroianni et al., 2015). For healthcare professionals, such attitudes can also be influenced by professional education and real-world clinical experiences(Wang et al., 2018)

Existing evidence in undergraduate nursing education suggests only low-tomoderate student knowledge about palliative care(Carroll et al., 2005; Brajtman et al., 2007; Al Qadire, 2014; Khraisat, Hamdan and Ghazzawwi, 2017). Knowledge does seem to improve as students' progress in their academic studies, but it still remains inadequate(Kwekkeboom, Vahl and Eland, 2006; Al Qadire, 2014). One explanation may be that undergraduate nursing curricula provide limited and/or inconsistent content about palliative and end-of-life care(Arber, 2001; Kwekkeboom, Vahl and Eland, 2006; Brajtman et al., 2007). Where theoretical and practical training on palliative care has been fully integrated in undergraduate nursing programmes, not only has it improved students' knowledge, but also led to more liberal attitudes towards death, dying and end-of-life care(Mastroianni et al., 2015; Chover-Sierra, Martínez-Sabater and Lapeña-Moñux, 2017). This can even mitigate the effects of factors, such as students' age, gender or previous experience of death in the family, that can influence how nurses develop positive or negative attitudes towards palliative and end-of-life care (Chover-Sierra, Martínez-Sabater and Lapeña-Moñux, 2017).

In Greece, due to lack of dedicated palliative care units, most patients with a lifelimiting illness receive care in general hospitals. This means that virtually all nurses are eligible to deal with the complexities of palliative and/or end-of-life care regardless of clinical setting, clinical experience, and/or specialization. There is thus a clear requirement to adequately prepare nursing students for this possible role. In the country's two University nursing faculties, palliative care undergraduate courses 
are offered in the $3^{\text {nd }}$ and $4^{\text {th }}$ year of the Adult Nursing BSc programme, and involve both taught and clinical placement activities. Thus far, no formal evaluation of undergraduate nursing students' palliative and end-of-life care competencies (knowledge and attitudes) has been performed. In this study, we aimed to address this gap. Secondarily, we explored students' demographic and academic factors as potential moderators of student knowledge and attitudes. Our research questions were as follows:

1. What is the level of knowledge about palliative care among $2^{\text {nd }}, 3^{\text {rd }}$ and $4^{\text {th }}$ year undergraduate nursing students?

2. What attitudes towards end-of-life care do $2^{\text {nd }}, 3^{\text {rd }}$ and $4^{\text {th }}$ year undergraduate nursing students hold?

3. What demographic, academic, education, and death experience covariates predict students' knowledge and attitudes?

4. Is student knowledge associated with student attitudes? If so, what are the effects of student knowledge on student attitudes, controlling for the effects of other covariates?

Our goal was to generate a first pool of evidence to help us identify training gaps and areas for improvement.

\section{Methods}

Study design

We employed a descriptive, cross-sectional, questionnaire-based survey design. We obtained ethical approval from the University Ethics Committees of both participating academic institutions.

\section{Participants and sampling}

We used a convenience sampling method. Students eligible for participation were:

- Enrolled in the undergraduate nursing programme at either the University of Athens (UoA) or the University of Peloponnese (UoP), and

- At the end of the $2^{\text {nd }}, 3^{\text {rd }}$ or $4^{\text {th }}$ academic year of undergraduate nursing studies.

We aimed to evaluate the knowledge and attitudes of students with some level of academic and/or clinical exposure to palliative/end-of-life care; therefore, we excluded first-year students because they are only taught general nursing/biomedical courses in the $1^{\text {st }}$ year.

\section{Procedures}

In agreement with course tutors, a researcher introduced the study to the students at the end of a class for each cohort. The researcher provided a general overview of the purpose and procedures of the study, and informed the students that participation was entirely voluntary and anonymous, and that non-participation would incur no penalty whatsoever. The researcher handed out written information sheets, consent forms, and questionnaire packs to all students. Those willing to participate 
signed the consent form and filled out the questionnaires in class. The researcher collected returned questionnaire packs in an opaque carton box that she kept with her. Consent forms were collected separately in a documents folder.

\section{Instrumentation}

A demographic form was used to collect data on students' age, gender, academic year, work experience, ethnicity, marital status, past attendance of seminars or lectures on palliative care, experience of death or end-of-life care while on clinical placement, and past experience of death or end-of-life care in the student's family.

The Palliative Care Quiz for Nursing (PCQN) assessed students' knowledge about palliative care(Ross, McDonald and McGuinness, 1996). The PCQN has 20 questions, which can be grouped in three categories (Table 1) and aggregated to yield a total score. Total scores can range from 0 (lowest level of knowledge) to 20 (highest level of knowledge). The internal consistency of the PCQN in this study was moderate (Kuder-Richardson 20 $=0.56$ ).

The Frommelt Attitudes Towards Care of the Dying (FATCOD)(Frommelt, 1991)assessed students' attitudes toward caring for dying patients. Scores from thirty questions are summed to calculate a total FATCOD score that ranges from 30 to 150 , with higher scores indicating more positive attitudes. The internal consistency of the FATCOD in this study was very good (Cronbach's alpha=0.81).

As no Greek version of either questionnaire was available, we translated both questionnaires as per ISPOR guidance(Wild et al., 2005) details of the translation and linguistic validation process will be reported elsewhere.

\section{Data analysis}

We conducted univariate analysis on all data, and generated frequency counts for each response on the PCQN and FATCOD to describe response patterns $(n, \%)$. Total scores were calculated for both measures, and described as mean, median, standard deviation and range. We used Q-Q plots, histograms and KolmogorovSmirnov tests to check the assumption of normality in total PCQN and FATCOD scores. We noted no deviations from normality. Age and working experience were highly positively skewed; therefore, we created two binary variables to classify students as 'young' (19-24 years old) v. 'mature' (25+ years old), and with no experience ( 0 years) $\mathrm{v}$. some working experience $(1+$ year). We also created two dummy variables ( $3^{\text {rd }}$ year; $4^{\text {th }}$ year) to allow inclusion of year of class in subsequent regression analyses. All other covariates were treated as binary variables.

We used linear regression analysis to examine the association between covariates and total PCQN and FATCOD scores. First, we built binary models for each individual covariate with either PCQN or FATCOD scores as the dependent variable. Covariates with a $p$-value $<0.20$ were then entered in the multivariate linear regression analysis, using the backward elimination method to yield the final model. We investigated assumptions relating to the normal distribution of errors and multicollinearity; no modifications to the analysis were required. Finally, we used hierarchical regression analysis to investigate the effects of students' knowledge on students' attitudes, controlling for the effects of other covariates entered in previous 
steps and reporting the relevant cumulative $\mathrm{R}^{2}$ and $\mathrm{R}^{2}$ change. We set the level of significance at 0.05. IBM SPSS (IBM Inc. Chicago, IL) aided the statistical analysis.

\section{Results}

Between May and June 2016, we received 529 questionnaire packs (response rate $=87.6 \%$ ), all of which were included in the final analysis. Respondents had a mean age of 21.7 years ( $S D=3.7$; range 19-64). About $5 \%$ were classified as "mature" students. Most respondents were female (84\%), single (98\%) and of Greek origin (97\%). Ninety-two percent had no previous working experience. (Table 1). Seventy-three per cent were UoA nursing students. Most respondents were either $2^{\text {nd }}(37 \%)$ or $4^{\text {th }}$ year students $(41 \%)$. Sample sizes and response rates by year of class and by institution are shown in Table 2.

Two in three respondents had received formal education as part of their undergraduate studies, while $23 \%$ had attended some extra-curricular seminar/workshop about palliative care. Only 18\% reported having attended both academic lectures and extra-curricular seminars/workshops. Thirty-seven percent experienced a patient's death while on clinical placement; over $40 \%$ had experienced the death of a family member or a friend. Just over $18 \%$ had both a patient and a family/friend death experience.

\section{Knowledge about palliative care}

Only $1.5 \%$ of respondents exceeded a cut-off score of 15 , indicating sufficient knowledge about palliative care; $19.6 \%$ had a total PCQN score greater than 10 . For most respondents, total PCQN scores were between 6 and 10 (64.7\%). (Table 1).

For six PCQN items (two on palliative care principles; four on pain management), $65 \%-85 \%$ of respondents provided correct answers (Figure 1). Conversely, between $68 \%$ and $99 \%$ of respondents provided incorrect answers on 11 PCQN items, predominantly those pertinent to knowledge about pain/symptom management. Knowledge on psychosocial/spiritual care was quite low on average.

\section{Attitudes towards end-of-life care}

No respondent had a FATCOD score below 76 (Table 1), but only $23.6 \%$ scored 120 and above. We found positive, liberal and supportive attitudes towards end-of-life care and its importance for the dying person and his/her family for the majority of respondents and FATCOD items (Table 3). Six in 10 respondents would be keen to care for a dying person and his/her family.

We did however note a certain degree of student discomfort, particularly in relation to direct care of a dying person and addressing queries and emotional reactions pertinent to an imminent death (\#3, 8, 11, 13-15, 26). Moreover, half the respondents viewed family members' close involvement in patient care as possibly interfering with the health professional's work. Close to $70 \%$ were unsure or disagreed about permitting the dying person and his/her family to be the primary decision-makers. However, over $85 \%$ disagreed that patients should be deprived of their right to make decisions about their physical care. 


\section{Predictors of student knowledge and attitudes}

Being a $4^{\text {th }}$ year student $(p<0.001)$, being a 'mature"' student $(p<0.001)$, and studying at UoA $(p<0.001)$ were the strongest predictors of higher knowledge about palliative care (Table 4). Work experience and a death experience either within family or while on placement did not significantly predict knowledge levels.

Studying at UoA $(p<0.001)$, being a 'mature' student $(p=0.014)$, and having received undergraduate education on palliative care $(b=3.82 ; p<0.001)$ were the strongest predictors of positive attitudes towards end-of-life care. Work experience, death experience while on placement and seminar attendance were not significant predictors.

\section{Knowledge as predictor of attitudes}

Greater knowledge about palliative care was moderately and significantly correlated to more positive attitudes towards end-of-life care $(r=0.35 ; p<0.001)$. The hierarchical regression model was statistically significant (Table 5), but only moderately successful in predicting students' attitudes towards end-of-life care, with an overall $R^{2}$ of 0.19 .

Controlling for the effects of other covariates, students' knowledge made only a modest contribution to explain the variance in attitudes towards end-of-life care, with an $R^{2}$ increment of 0.04 . However, a 1-point increase in PCQN scores was predictive of an almost 1-point increase in FATCOD scores $(p<0.001)$.

\section{Discussion}

Our student sample held predominantly positive attitudes towards end-of-life care despite the observed gaps in knowledge about palliative care. Academic parameters and student demographic characteristics were the most significant moderators of both knowledge and attitudes. Greater knowledge about palliative care was a relatively weak, yet significant, predictor of more liberal attitudes towards care of the dying.

With a mean total knowledge score of 8.2 , our student sample's knowledge levels are not unlike those fairly low reported in previous studies with Jordanian (8) (Al Qadire, 2014) French (9.2) (Carroll et al., 2005), Canadian (12.9) (Brajtman et al., 2007) and Saudi Arabian (7.3)(Khraisat, Hamdan and Ghazzawwi, 2017) nursing students. Possible reasons for such low scores may be the presence or absence, or quality of palliative care courses in undergraduate nursing programmes.

For us, particularly in light of integration of dedicated undergraduate courses and clinical placement, that student knowledge about palliative care remains low is troubling. However, most students did seem to possess good knowledge on the very basic principles of palliative care and pain management, which is somewhat encouraging. Perhaps, more advanced knowledge on pain/symptom management can be consolidated through Continuing Professional Development (CPD) activities and active clinical practice. That said, students' seemingly poor knowledge regarding use of "Demerol" (i.e. meperidine or pethidine) can be explained as lack of familiarity with a brand name that is not widely used in Greece. In previous studies, "Demerol" 
was replaced with the term "pethidine" (Arber, 2001; Al Qadire, 2014) we are incorporating this modification in the Greek PCQN. In addition, that only $30 \%$ of our sample saw palliative care as compatible to aggressive treatment can be attributed to the negative connotation of the term "aggressive". Similar response rates were reported among French (25\%) (Carroll et al., 2005) and Jordanian (33\%) nursing students (Al Qadire, 2014). Arber (2001) replaced this term with "active" to more correctly convey the core message that palliative care incorporates elements similar to that of active treatment (Arber, 2001).

Our findings also point to some key student misconceptions that need addressed at the undergraduate level. Consistently, students seemed to believe that burnout is inevitable for palliative care professionals, that loss of distant relationships is easier to deal with, or that remaining at the bedside until death occurs is absolutely crucial and expected for family members. Regarding the latter, while most similar studies yielded opposite responses (Carroll et al., 2005; Brajtman et al., 2007; Al Qadire, 2014; Khraisat, Hamdan and Ghazzawwi, 2017), studies with Korean(Kim et al., 2012)and Spanish(Chover-Sierra, Martínez-Sabater and Lapeña-Moñux, 2017) nurses did reflect similar opinions. Cultural/religious factors that shape the society's expectations and fundamental role of the family in the care of the dying patient may have played a role(Kim et al., 2012). Targeting unhelpful assumptions around palliative care, death and dying, and its impact on patients, families, and health professionals should be a priority in undergraduate nursing education.

Mean attitude scores in our student sample were similar to first-year Swedish nursing students(Hagelin et al., 2016), lower than scores of Canadian nursing students(Brajtman et al., 2007), but higher than scores of Turkish (Arslan et al., 2014) and Palestinian nursing students(Abu-El-Noor and Abu-El-Noor, 2016). Future international studies or meta-analyses could clarify the role of culture on these observed differences.

In line with current evidence(Brajtman et al., 2007; Abu-El-Noor and Abu-El-Noor, 2016; Hagelin et al., 2016), our student sample did seem to believe that end-of-life care is a worthwhile experience. However, there was a clear indication of lack of comfort when actually caring for a dying person and/or witnessing his/her death (Brajtman et al., 2007). Undergraduate nursing education should focus on training/activities that prepare student nurses to psychologically deal with sensitive and challenging processes and situations, such as death and dying.

In terms of potential moderators of knowledge and attitudes, we concur with the current evidence base. Older age significantly predicted greater knowledge and more liberal attitudes towards end-of-life care(Barrere, Durkin and LaCoursiere, 2008; Lange, Thom and Kline, 2008). A combination of accumulated life experiences, mental maturity and information absorption that accompany biological and professional aging can explain this finding. Academic year also seems to play role, particularly in relation to knowledge gain. Not only that, but previous studies have shown that attitudes towards care of a dying patient become more open and positive at the final year of studies (Henoch et al., 2017). CPD activities and formal education(Hagelin et al., 2016) can have an additional positive influence on students' attitudes towards end-of-life care.

Having cared for or experienced the death of a family member can be a significant predictor of student nurses' attitudes towards palliative care(Arslan et al., 2014; Grubb and Arthur, 2016; Hagelin et al., 2016). Such factors-experiences can have a 
strong effect on student nurses' attitudes towards end-of-life care, perhaps stronger than knowledge itself. However, with only $19 \%$ of the variance in students' attitudes explained by our set of predictors, a question remains about what other factors might play a role in shaping students' views and beliefs towards end-of-life care. We did consider marital status as a potential moderator, but heterogeneity in our sample was not enough to allow us to perform any sub-group analyses. Spirituality/religiousness might be another such variable, given that Arslan (2014) found that Atheists were less positive about the care of the dying patient. Type of personality, philosophical stance towards life, or experience as the primary (formal or informal) caregiver of a person with a life-limiting illness could be additional factors.

Some less straightforward to interpret findings also warrant comment. We found that female nursing students were more knowledgeable and held more positive attitudes compared to male students. The effects of gender on attained knowledge are difficult to explain; however, similar findings do exist (Frommelt, 2003). Neither working experience nor experience of a patient's death while on placement were significant predictors of students' knowledge or attitudes. Longer clinical experience can help consolidate clinical knowledge and cultivate more positive caring attitudes(Grubb and Arthur, 2016) but it might not automatically guarantee such qualities. It might be that actual involvement in end-of-life clinical care has a stronger influence than "any" type of clinical experience. Relatedly, experiencing a patient's death during clinical training, albeit stressful (Edo-Gual et al., 2014) might not in itself be a strong cue to trigger an end-of-life care "mentality" among student nurses. Finally, UoA students scored higher on both outcome measures compared to UoP students. In Greece, similar to other countries(EAPC 2004;Cavaye and Watts, 2012), undergraduate nursing education is delivered inconsistently across faculties. Palliative care courses are mandatory only at UoA, whereas at UoP the course is provided as a number of discretionary lectures. Together, these observations call for collaborative planning and deployment to ensure consistency in both content and anticipated outcomes.

\section{Strengths and Limitations}

The authors did not identify any other studies that evaluated undergraduate student nurses' knowledge about palliative care and attitudes towards end-of-life care in Greece. We involved three large cohorts from two academic institutions that, served by a satisfactory response rate, contributed to a large survey sample with evident heterogeneity in certain categories of student characteristics. In addition, we used two well-developed and validated questionnaires that we translated into Greek in line with current recommendations. This approach ensured internal validity for our study and enhanced comparability of our findings with existing evidence.

A number of limitations must also be considered. Our student sample is hardly representative of all nursing students in a given academic year in Greece. This is because, in addition to the two University faculties, another eight nursing faculties operate within higher technological institutions across the country. Diversity in the content of lectures or courses on palliative care exists within these faculties, which may contribute to student knowledge and attitudes that may well differ from our sample. Internal consistency for the PCQN was below the minimum acceptable value of 0.70 (Streiner, 2003), which is indicative of low internal consistency. Based on our findings, we are introducing some minor modifications to the Greek PCQN to enhance clarity; these hopefully will increase the questionnaire's reliability in future 
studies. Not much heterogeneity was achieved for age, working experience, ethnicity or marital status. This has led to very small-sized sub-groups (only $2-8 \%$ of sample) that rendered data analysis somewhat challenging. The researcher and lecturer invigilated all participating students to prevent student collusion during questionnaire completion in the classroom. However, we cannot rule out the possibility that, to a certain (minimal) extent, student collusion might have actually taken place, thus influencing our findings. Finally, this was a cross-sectional study that only captured a snapshot of students' competencies in a specific academic year. We are thus unable to comment on changes in knowledge and attitudes as students' progress in their studies. However, we are currently following up this project with a large longitudinal study to investigate over-time change in students' knowledge and attitudes from year of entry to end of undergraduate studies.

\section{Conclusions}

This study has generated a rich dataset to form a first pool of evidence to help us identify training gaps and areas for improvement in educating undergraduate nursing students about palliative and end-of-life care. Knowledge about palliative care among undergraduate nursing students remained relatively poor overall, but was greater with student age and academic year of study. Attitudes towards end-of-life care were generally liberal, improved as students progressed in their studies, yet still reflected an evident lack of comfort in dealing with death and dying. Our findings suggest that structured courses in palliative care can be a core part of undergraduate nursing education. Specific attention could be given to such areas patient-health professional communication, misconceptions and biases towards death and dying, and comfort in caring for the dying in order to prepare student nurses to psychologically deal with the sensitive and challenging process of death and dying.

\section{Acknowledgments}

We would like to thank undergraduate nursing students at UoA and UoP for taking part in this study. 


\section{REFERENCES}

Abu-El-Noor, N. I. and Abu-El-Noor, M. K. (2016) 'Attitude of Palestinian Nursing Students Toward Caring for Dying Patients', Journal of Holistic Nursing. doi: 10.1177/0898010115596492.

Araujo Sadala, M. L. and Machado da Silva, F. (2009) 'Taking care of terminal patients: nursing students' perspective.', Revista Escola Enfermagem USP.

Arber, A. (2001) 'Student nurses' knowledge of palliative care: evaluating an education module', International Journal of Palliative Nursing. doi: 10.12968/ijpn.2001.7.12.9284.

Arslan, D. et al. (2014) 'Student Nurses' Attitudes Toward Dying Patients in Central Anatolia', International Journal of Nursing Knowledge. doi: 10.1111/20473095.12042.

Barrere, C. C., Durkin, A. and LaCoursiere, S. (2008) 'The influence of end-of-life education on attitudes of nursing students.', International journal of nursing education scholarship. doi: 10.2202/1548-923X.1494.

Brajtman, S. et al. (2007) 'Providing direction for change: assessing Canadian nursing students learning needs.', International journal of palliative nursing. doi: 10.12968/ijpn.2007.13.5.23491.

Carroll, G. et al. (2005) 'The French version of the palliative care quiz for nursing (PCQN-F): Development and evaluation', Journal of Palliative Care.

Cavaye, J. and Watts, J. H. (2012) 'End-of-life education in the pre-registration nursing curriculum: Patient, carer, nurse and student perspectives', Journal of Research in Nursing. doi: 10.1177/1744987110379531.

Chover-Sierra, E., Martínez-Sabater, A. and Lapeña-Moñux, Y. (2017) 'Knowledge in palliative care of nursing professionals at a Spanish hospital', Revista LatinoAmericana de Enfermagem. doi: 10.1590/1518-8345.1610.2847.

Edo-Gual, M. et al. (2014) 'The impact of death and dying on nursing students: An explanatory model', Journal of Clinical Nursing. doi: 10.1111/jocn.12602.

Etkind, S. N. et al. (2017) 'How many people will need palliative care in 2040? Past trends, future projections and implications for services', BMC Medicine. doi: 10.1186/s12916-017-0860-2.

Frommelt, K. H. M. (1991) 'The effects of death education on nurses' attitudes toward caring for terminally ill persons and their families', American Journal of Hospice and Palliative Medicine. doi: 10.1177/104990919100800509.

Frommelt, K. H. M. (2003) 'Attitudes toward care of the terminally ill: an educational intervention.', The American journal of hospice \& palliative care. doi: 10.1177/104990910302000108.

Grubb, C. and Arthur, A. (2016) 'Student nurses' experience of and attitudes towards care of the dying: A cross-sectional study', Palliative Medicine. doi: 10.1177/0269216315616762.

Hagelin, C. L. et al. (2016) 'Factors influencing attitude toward care of dying patients in first-year nursing students', International Journal of Palliative Nursing. doi: 
Henoch, I. et al. (2017) 'Undergraduate nursing students' attitudes and preparedness toward caring for dying persons - A longitudinal study', Nurse Education in Practice. doi: 10.1016/j.nepr.2017.06.007.

Khraisat, O. M., Hamdan, M. and Ghazzawwi, M. (2017) 'Palliative Care Issues and Challenges in Saudi Arabia', Journal of Palliative Care. doi: 10.1177/0825859717743229.

Kim, B. H. et al. (2012) 'Evaluation of End-of-Life Nursing Education ConsortiumGeriatric Train-the-Trainer Program in Korea.', Korean Journal of Adult Nursing. doi: 10.7475/kjan.2012.24.4.390.

Kwekkeboom, K. L., Vahl, C. and Eland, J. (2006) 'Impact of a volunteer companion program on nursing students' knowledge and concerns related to palliative care', Journal of Palliative Medicine. doi: 10.1089/jpm.2006.9.90.

Lange, M., Thom, B. and Kline, N. E. (2008) 'Assessing Nurses' Attitudes Toward Death and Caring for Dying Patients in a Comprehensive Cancer Center', Oncology Nursing Forum. doi: 10.1188/08.ONF.955-959.

Mastroianni, C. et al. (2015) 'Frommelt attitudes toward care of the dying scale form B: Psychometric testing of the Italian version for students', Omega (United States). doi: $10.1177 / 0030222815568944$.

Mutto, E. M. et al. (2010) 'Nursing Education: The Experience, Attitudes, and Impact of Caring for Dying Patients by Undergraduate Argentinian Nursing Students', Journal of Palliative Medicine. doi: 10.1089/jpm.2010.0301.

Al Qadire, M. (2014) 'Knowledge of palliative care: An online survey', Nurse Education Today. doi: 10.1016/j.nedt.2013.08.019.

Ross, M. M., McDonald, B. and McGuinness, J. (1996) 'The palliative care quiz for nursing (PCQN): the development of an instrument to measure nurses' knowledge of palliative care.', Journal of Advanced Nursing. doi: 10.1111/j.13652648.1996.tb03106.x.

Streiner, D. L. (2003) 'Starting at the beginning: An introduction to coefficient alpha and internal consistency', Journal of Personality Assessment. doi: 10.1207/S15327752JPA8001_18.

Wang, L. et al. (2018) 'Clinical nurses' attitudes towards death and caring for dying patients in China', International Journal of Palliative Nursing. doi: 10.12968/ijpn.2018.24.1.33.

Wang, L. P. et al. (2016) 'Development and Psychometric Testing Chinese Version of the Frommelt Attitude Toward Care of the Dying Scale, Form B in Nurses and Nursing Students', Journal of Cancer Education. doi: 10.1007/s13187-015-0810-7.

Wild, D. et al. (2005) 'Principles of good practice for the translation and cultural adaptation process for patient-reported outcomes (PRO) measures: Report of the ISPOR Task Force for Translation and Cultural Adaptation', Value in Health. doi: 10.1111/j.1524-4733.2005.04054.x. 
EAPC (2004) 'A guide for the development of Palliative Nurse Education in Europe' available online http://www.eapcnet.eu/LinkClick.aspx?fileticket=e9JnEa7YZDM\%3D

\section{Tables}

Table 1. Background characteristics of the study sample $(n=529)$ and summaries of PCQN and FATCOD total scores

\begin{tabular}{|c|c|c|}
\hline Variable & Mean (SD); Median & Min-Max \\
\hline Age (years) & $21.7(3.7) ; 21.0$ & 19-64 \\
\hline Working experience (years) & $0.4(2.3) ; 0.0$ & $0-27$ \\
\hline PCQN total score (possible range $0-20$ ) & $8.2(2.8) ; 8.0$ & $1-17$ \\
\hline $\begin{array}{l}\text { PCQN1: Philosophy and principles (\#1, 9, 12, 17; possible } \\
\text { range 0-4) }\end{array}$ & $1.9(0.9) ; 2.0$ & $0-4$ \\
\hline $\begin{array}{l}\text { PCQN2: Control of pain and other symptoms (\#2-4, 6-8, 10, } \\
\text { 13-16, 18, 20; possible range 0-13) }\end{array}$ & $5.5(2.3) ; 5.0$ & $1-12$ \\
\hline $\begin{array}{l}\text { PCQN3: Psychosocial aspects }((\# 5,11,19 ; \text { possible range } \\
0-3)\end{array}$ & $0.8(0.7) ; 1.0$ & $0-3$ \\
\hline FATCOD total score (possible range $30-150$ ) & 111.9 (10.2); 111.0 & $76-141$ \\
\hline Variable & $\mathbf{N}$ & $\%$ \\
\hline \multicolumn{3}{|l|}{ Gender } \\
\hline Female & 444 & 83.9 \\
\hline \multicolumn{3}{|l|}{ Age classification } \\
\hline Young student (19-24 years old) & 505 & 95.5 \\
\hline Mature student $(25+$ years old $)$ & 24 & 4.5 \\
\hline \multicolumn{3}{|l|}{ Working experience classification } \\
\hline None (0 years) & 486 & 91.9 \\
\hline Some $(1+$ years $)$ & 43 & 8.1 \\
\hline \multicolumn{3}{|l|}{ Ethnicity } \\
\hline Greek & 511 & 96.6 \\
\hline Other & 18 & 3.4 \\
\hline \multicolumn{3}{|l|}{ Marital Status } \\
\hline Single & 518 & 97.9 \\
\hline Married/partnered & 8 & 1.5 \\
\hline Other & 3 & 0.6 \\
\hline \multicolumn{3}{|l|}{ Attended seminar/lecture on palliative care in the past } \\
\hline Yes & 124 & 23.4 \\
\hline \multicolumn{3}{|l|}{ Received education on end-of-life care during undergraduate studies } \\
\hline Yes & 341 & 64.5 \\
\hline \multicolumn{3}{|l|}{ Experienced death of patient during clinical placement } \\
\hline Yes & 194 & 36.7 \\
\hline \multicolumn{3}{|l|}{ Experienced death of family member/friend in the past } \\
\hline Yes & 223 & 42.2 \\
\hline \multicolumn{3}{|l|}{ PCQN total score categories } \\
\hline $0-5$ & 83 & 15.7 \\
\hline $6-10$ & 342 & 64.7 \\
\hline $11-14$ & 96 & 18.1 \\
\hline $15+$ (sufficient knowledge) & 8 & 1.5 \\
\hline
\end{tabular}


Table 2. Sample sizes and response rates by year of class and by institution.

\begin{tabular}{|c|c|c|c|c|c|c|c|c|}
\hline \multirow{3}{*}{ Year of Class } & \multirow{2}{*}{\multicolumn{2}{|c|}{ Total sample }} & \multicolumn{6}{|c|}{ By place of study } \\
\hline & & & \multicolumn{3}{|c|}{ University of Athens } & \multicolumn{3}{|c|}{ University of Peloponnese } \\
\hline & $\mathbf{n}$ & $\%$ & $\mathbf{n}$ & $\%$ & \% RR & $\mathbf{n}$ & $\%$ & \% RR \\
\hline $2^{\text {nd }}$ year & 198 & 37.4 & 163 & 42.0 & 92.0 & 35 & 24.8 & 85.0 \\
\hline $3^{\text {rd }}$ year & 112 & 21.2 & 77 & 19.8 & 70.0 & 35 & 24.8 & 85.0 \\
\hline $4^{\text {th }}$ year & 219 & 41.4 & 148 & 38.1 & 95.0 & 71 & 50.4 & 98.0 \\
\hline Totals & 529 & & 388 & 73.3 & & 141 & 26.7 & \\
\hline
\end{tabular}


Table 3.Response frequencies on the FATCOD scale*.

FATCOD Item

\begin{tabular}{|c|c|c|c|}
\hline Mean (SD) & $\begin{array}{c}\text { \% } \\
\text { Disagreel } \\
\text { Strongly } \\
\text { disagree }\end{array}$ & $\begin{array}{c}\% \\
\text { Unsure }\end{array}$ & $\begin{array}{c}\% \\
\text { Agreel } \\
\text { Strongly } \\
\text { agree }\end{array}$ \\
\hline $4.11(0.87)$ & 4.9 & 11.0 & 84.1 \\
\hline 3.41 (1.14) & 23.8 & 20.4 & 55.8 \\
\hline $2.83(1.08)$ & 29.1 & 30.8 & 40.1 \\
\hline $4.24(0.87)$ & 5.1 & 10.4 & 84.5 \\
\hline $3.75(0.97)$ & 62.0 & 28.0 & 10.0 \\
\hline $3.65(0.92)$ & 61.1 & 28.3 & 10.6 \\
\hline $3.66(0.83)$ & 57.3 & 36.8 & 5.9 \\
\hline $2.35(0.91)$ & 13.4 & 19.6 & 67.0 \\
\hline $3.73(0.99)$ & 70.1 & 15.8 & 14.1 \\
\hline $4.01(0.76)$ & 4.5 & 11.5 & 84.0 \\
\hline $3.56(0.96)$ & 58.0 & 26.7 & 15.3 \\
\hline $4.14(0.69)$ & 2.3 & 10.2 & 87.5 \\
\hline $3.40(0.94)$ & 47.5 & 37.6 & 14.9 \\
\hline $3.46(0.99)$ & 53.5 & 26.5 & 20.0 \\
\hline $3.61(0.94)$ & 56.5 & 32.5 & 11.0 \\
\hline $4.40(0.66)$ & 1.7 & 3.2 & 95.1 \\
\hline $3.84(0.87)$ & 70.3 & 22.5 & 7.2 \\
\hline $4.51(0.65)$ & 1.2 & 3.2 & 95.6 \\
\hline $4.29(0.86)$ & 85.8 & 9.3 & 4.9 \\
\hline $4.37(0.67)$ & 1.5 & 4.7 & 93.8 \\
\hline $4.40(0.69)$ & 1.9 & 3.4 & 94.7 \\
\hline $4.40(0.65)$ & 1.3 & 5.2 & 93.5 \\
\hline $4.05(0.80)$ & 3.5 & 18.0 & 78.5 \\
\hline $3.21(0.89)$ & 20.7 & 39.1 & 40.2 \\
\hline 3.15 (1.14) & 29.7 & 32.5 & 37.8 \\
\hline $2.68(1.03)$ & 51.8 & 23.1 & 25.1 \\
\hline $4.03(0.77)$ & 2.4 & 20.4 & 77.2 \\
\hline $3.99(0.88)$ & 76.8 & 16.8 & 6.4 \\
\hline $2.65(0.87)$ & 16.1 & 31.9 & 52.0 \\
\hline $4.03(0.63)$ & 1.9 & 11.2 & 86.9 \\
\hline
\end{tabular}

1. Giving care to the dying person is a worthwhile experience

2. Death is not the worst thing that can happen to a person.

3. I would be uncomfortable talking about impending death with the dying person.

4. Caring for the patient's family should continue throughout the period of grief and bereavement.

5. I would not want to care for a dying person.

6. The non-family caregivers should not be the one to talk about death with the dying person.

7. The length of time required to give care to a dying person would frustrate me.

8. I would be upset when the dying person I was caring for gave up hope of getting better.

9. It is difficult to form a close relationship with the dying person.

10. There are times when death is welcomed by the dying person.

11. When a patient asks, "Am I dying?" I think it is best to change the subject to something cheerful.

12. The family should be involved in the physical care (feeding, personal hygiene) of the dying person.

13. I would hope the person I'm caring for dies when I am not present.

14. I am afraid to become friends with a dying person

15. I would feel like running away when the person actually died

16. Families need emotional support to accept the behavior changes of the dying person.

17. As a patient nears death, the non-family caregiver should withdraw from his or her involvement with the patient.

18. Families should be concerned about helping their dying member make the best of his or her remaining life.

19. The dying person should not be allowed to make decisions about his or her physical care.

20. Families should maintain as normal an environment as possible for their dying member.

21. It is beneficial for the dying person to verbalize his or her feelings.

22. Care should extend to the family of the dying person.

23. Caregivers should permit dying persons to have flexible visiting schedules.

24. The dying person and his or her family should be the incharge decision makers.

25. Addiction to pain relieving medication should not be a concern when dealing with a dying person.

26. I would be uncomfortable if I entered the room of a terminally ill person and found him/her crying

27. Dying persons should be given honest answers about their condition.

28. Educating families about death and dying is not a non-family caregiver's responsibility.

29. Family members who stay close to a dying person often interfere with the professional's job with the patient.

30. It is possible for non-family caregivers to help patients prepare for death.

Note: Green indicates positive attitudes endorsed by $\geq 50 \%$ of respondents. Amber indicates negative attitudes or ambivalence endorsed by a sizeable proportion (15-49\%) of the sample, or positive attitudes endorsed by $<50 \%$ of the sample. Red indicates negative attitudes endorsed by the majority of respondents. 
Table 4. Multivariate linear regression models of PCQN and FATCOD scores.

\begin{tabular}{|c|c|c|c|c|c|c|c|c|}
\hline \multirow[b]{2}{*}{ Predictor variable } & \multicolumn{4}{|c|}{$\begin{array}{c}\text { Knowledge about palliative care } \\
\text { (PCQN) }\end{array}$} & \multicolumn{4}{|c|}{$\begin{array}{l}\text { Attitudes towards end-of-life care } \\
\text { (FATCOD) }\end{array}$} \\
\hline & $\boldsymbol{b}$ & $S E$ & $\beta$ & $t$ & b & SE & $\hat{\beta}$ & $t$ \\
\hline Constant & 5.45 & 0.71 & & $7.65^{\star \star}$ & 103.39 & 3.11 & & $33.21^{\star *}$ \\
\hline Gender (ref: male) & 0.64 & 0.26 & 0.08 & $2.47^{*}$ & 2.59 & 1.14 & 0.09 & $2.28^{\star}$ \\
\hline Age classification (ref: young) & 1.64 & 0.46 & 0.12 & $3.57^{\star *}$ & 4.92 & 2.00 & 0.10 & $2.46^{*}$ \\
\hline Working experience class. (ref: none) & & & 0.05 & 1.17 & - & - & - & - \\
\hline Place of study (ref: UoA) & -1.53 & 0.22 & -0.24 & $-7.10^{\star *}$ & -5.07 & 0.95 & -0.22 & $-5.36^{\star \star}$ \\
\hline $3^{\text {rd }}$ year of class: dummy 1 (ref: $2^{\text {nd }}$ year) & 0.54 & 0.27 & 0.08 & $1.98^{*}$ & 2.39 & 1.19 & 0.10 & $2.01^{*}$ \\
\hline $4^{\text {th }}$ year of class: dummy 2 (ref: $2^{\text {nd }}$ year) & 2.97 & 0.27 & 0.53 & $11.08^{\star \star}$ & 2.91 & 1.14 & 0.14 & $2.56^{\star}$ \\
\hline Death experience: placement (ref: No) & & & -0.01 & -0.28 & & & 0.06 & 1.35 \\
\hline Death experience: family (ref: No) & & & 0.02 & 0.58 & 2.08 & 0.85 & 0.10 & $2.46^{\star}$ \\
\hline Education on PC: seminar (ref: No) & 0.54 & 0.24 & 0.08 & $2.28^{*}$ & & & 0.02 & 0.49 \\
\hline Education on PC: curriculum (ref: No) & 0.55 & 0.24 & 0.10 & $2.32^{*}$ & 3.82 & 1.04 & 0.18 & $3.67^{\star \star}$ \\
\hline Model statistics & \multicolumn{4}{|c|}{$\begin{array}{c}\text { Overall } R^{2}=0.40 ; \text { Adjusted } R^{2}=0.39 \\
F(10,518)=34.89^{\star *}\end{array}$} & \multicolumn{4}{|c|}{$\begin{array}{c}\text { Overall } R^{2}=0.15 ; \text { Adjusted } R^{2}=0.14 ; F \\
(9,519)=10.36^{\star \star}\end{array}$} \\
\hline \multicolumn{9}{|c|}{ 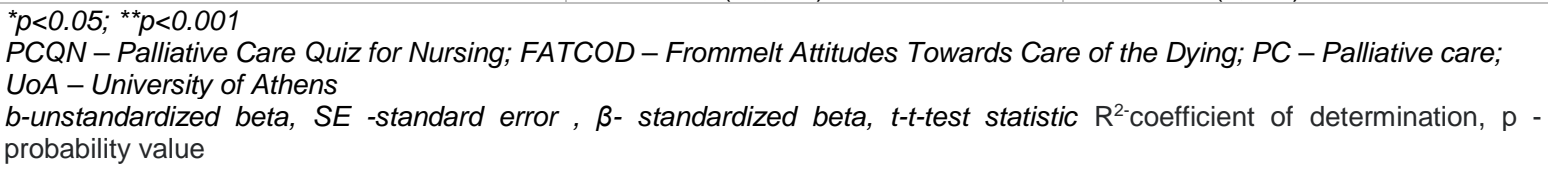 } \\
\hline
\end{tabular}


Table 5. Hierarchical regression analysis of FATCOD scores on PCQN scores, controlled for covariates.

\begin{tabular}{|c|c|c|c|c|c|c|}
\hline \multirow[b]{2}{*}{ Step } & \multirow[b]{2}{*}{ Predictor variable } & \multicolumn{5}{|c|}{ Attitudes towards end-of-life care (FATCOD) } \\
\hline & & $\boldsymbol{b}$ & SE & $\beta$ & $t$ & $R^{2}$ change \\
\hline \multirow[t]{3}{*}{1} & Demographic characteristics & & & & & $0.03^{\star}$ \\
\hline & Gender (ref: male) & 2.75 & 1.20 & 0.10 & $2.30^{*}$ & \\
\hline & Age classification (ref: young) & 5.77 & 2.12 & 0.12 & $2.73^{*}$ & \\
\hline \multirow[t]{4}{*}{2} & Academic characteristics & & & & & $0.09^{\star *}$ \\
\hline & Place of study (ref: UoA) & -5.26 & 0.96 & -0.23 & $-5.47^{\star \star}$ & \\
\hline & $3^{\text {rd }}$ year of class: dummy 1 (ref: $2^{\text {nd }}$ year) & 3.83 & 1.15 & 0.15 & $3.33^{*}$ & \\
\hline & $4^{\text {th }}$ year of class: dummy 2 (ref: $2^{\text {nd }}$ year) & 5.31 & 0.96 & 0.26 & $5.53^{\star \star}$ & \\
\hline \multirow[t]{3}{*}{3} & Death experience & & & & & $0.01^{*}$ \\
\hline & Death experience: placement (ref: No) & 1.02 & 0.95 & 0.05 & 1.07 & \\
\hline & Death experience: family (ref: No) & 2.12 & 0.86 & 0.10 & $2.47^{*}$ & \\
\hline \multirow[t]{3}{*}{4} & Education on palliative care & & & & & $0.02^{\star}$ \\
\hline & Education on PC: seminar (ref: No) & 0.66 & 1.04 & 0.03 & 0.64 & \\
\hline & Education on PC: curriculum (ref: No) & 3.94 & 1.04 & 0.19 & $3.78^{\star \star}$ & \\
\hline \multirow[t]{3}{*}{5} & Knowledge about palliative care & & & & & $0.04^{\star *}$ \\
\hline & PCQN & 0.94 & 0.19 & 0.26 & $4.99^{\star \star}$ & \\
\hline & Cumulative $\mathrm{R}^{2}$ & & & & & 0.19 \\
\hline \multicolumn{7}{|c|}{ 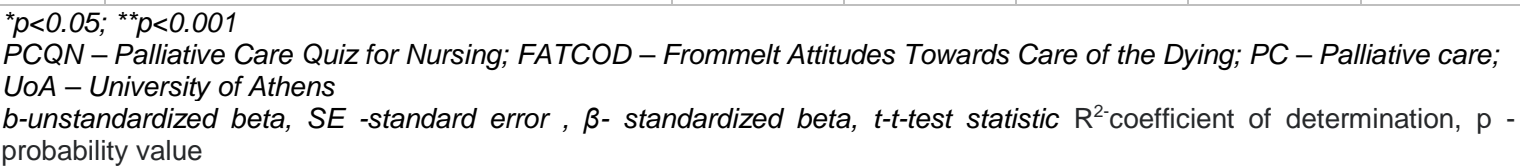 } \\
\hline
\end{tabular}

\section{Figures}

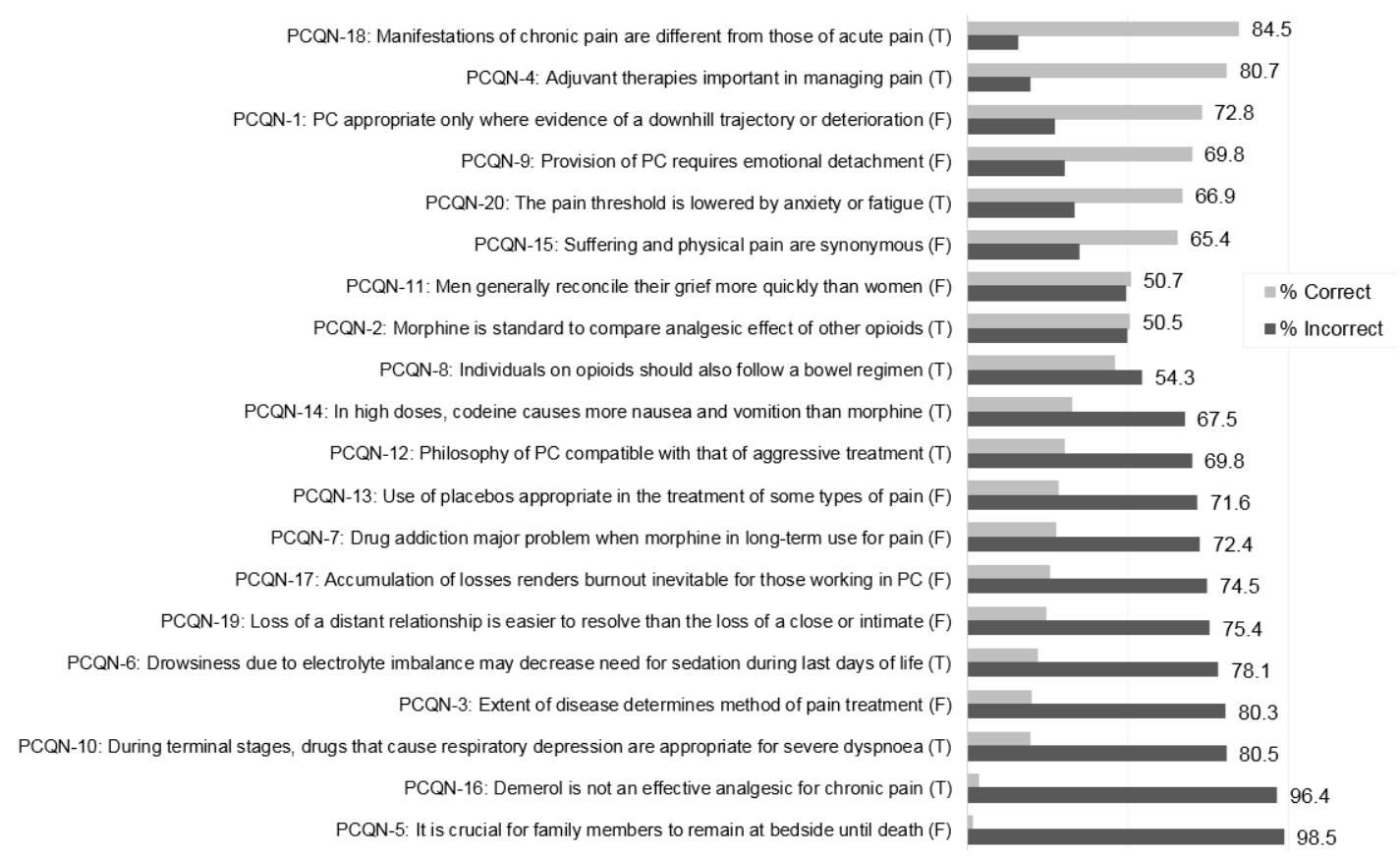

Figure 1. Frequencies of correct and incorrect answers on the Palliative Care Quiz for Nursing (PCQN) scale. T - True; F - False. 